\title{
Liquid-solid interaction during formation of nanocomposite systems
}

\author{
Ihor Shtablavyi ${ }^{1 *}$, Stepan Mudry', Paweł Kajak² \\ ${ }^{1}$ Ivan Franko National University of Lviv, Department for Metal Physics, Kyrylo and Mephodii 8, Ua-79005 Lviv, Ukraine \\ ${ }^{2}$ Gdansk University of Technology, Department of Solid State Physics, Faculty of Applied Physics and Mathematics, ul. Naru- \\ towicza 11/12, 80-233 Gdańsk, Poland \\ "Corresponding: author: sihor@ukr.net
}

\begin{abstract}
Structural changes in mixtures of liquid $\mathrm{Bi}$ with small $\mathrm{Cu}$ and $\mathrm{Ni}$ particles were studied at temperatures of 615 and $1145 \mathrm{~K}$. Microstructures of the composites were observed (SEM) and analyzed after treatment at different temperatures and various durations of stirring. The structure of the mixtures of $\mathrm{Bi}$ with $\mathrm{Cu}(\mathrm{Ni})$ particles was investigated by means of X-ray diffraction, both in the solid and liquid state.
\end{abstract}

Keywords: composite materials; liquid metals and alloys; metallic powders; microstructure; short-range order.

\section{INTRODUCTION}

Metal composite materials have found application in many areas of daily life for quite some time. A large number of composite materials have metallic matrices reinforced with high-strength, high-modulus and often brittle ceramic or metallic phase particles ${ }^{\mathbf{1}, 2}$. The particular benefits exhibited by metal matrix composites, such as lower density, increased specific strength and stiffness, increased high-temperature performance limits, and improved wear-abrasion resistance, are dependent on the properties of the matrix alloy and of the reinforcing phase ${ }^{3}$. Furthermore, composite systems with a liquid matrix have recently attracted the attention of researchers due to their potential practical applications. For instance, mixtures such as ferrocolloid suspensions have already been used in various fields 9 . In this case it is important to avoid the particle-particle and particlematrix interactions. Sometimes, however, such interaction may be desired in order to produce inter-phase boundaries using the liquid-solid reaction.

Several reviews are available on the processing and properties of composites, as well as on the interfacial phenomenon, which occurs in them ${ }^{4-8}$. At present, several methods for the processing of composite materials are available, however, on a large scale composites are produced by liquid metallurgy or powder metallurgy. In the former, the particulate phases are dispersed in the liquid before the solidification of the melt. It is clear that the mixture of melt and solid powder should transit to an equilibrium state by means of a diffusive process. Depending on the inclination towards chemical interaction between constituents, and on the temperature, powder size, duration of the solid-liquid reaction etc., such mixture attempts to form a homogeneous phase whose properties are different from those of the individual components. In this work we describe structural studies of metallic melts, in volume of which the micro- and nano-sized powder was introduced, performed in order to insight into the impact of interactions on the formation of metal matrix composites reinforced with metallic phases. We focused on $\mathrm{Cu}$ and $\mathrm{Ni}$ particles dispersed in a Bi-matrix.

As evidenced by the phase diagram ${ }^{\mathbf{1 0}}$, formation of chemical compounds was not observed in the $\mathrm{Bi}-\mathrm{Cu}$ system, and between the solidus and liquidus lines there exists a mixture of liquid bismuth and crystalline copper. The addition of small particles of copper to bismuth and subsequent heating of the composite between the solidus and liquidus lines should lead to a decrease in the content of crystalline copper and to an increase in its concentration in the melt. Above the melting point all the copper is in the melt. Therefore, by varying the temperature of the melt and the duration of ageing in the liquid state we can control the size of $\mathrm{Cu}$ particles in the Bi matrix.

In contrast to the $\mathrm{Bi}-\mathrm{Cu}$ system, in the Bi-Ni system the formation of two chemical compounds $\left(\mathrm{Bi}_{3} \mathrm{Ni}\right.$ and $\mathrm{BiNi}$ ) is observed ${ }^{\mathbf{1 0}}$. When the concentration of nickel is less than 25 at\%, the Bi-Ni melt will contain the $\mathrm{Bi}_{3} \mathrm{Ni}$ crystalline phase in the interval between the solidus line and $740 \mathrm{~K}$. Above $740 \mathrm{~K}$ and up to the melting point, the Bi-Ni melt will contain the BiNi crystalline phase. Upon the addition of nickel particles to the liquid bismuth, the system will try to reach equilibrium. If the concentration of nickel is less than 25 at $\%$, in the interaction process of crystalline $\mathrm{Ni}$ with liquid $\mathrm{Bi}, \mathrm{Bi}_{3} \mathrm{Ni}$ will be formed. Therefore, as in the previous case, by varying the temperature of the melt and the duration of ageing in the liquid state we can control the size of Ni particles and the content of $\mathrm{Bi}_{3} \mathrm{Ni}$ in the $\mathrm{Bi}$ matrix.

In two subsequent sections we describe our experiments, and present and discuss the obtained results. The final section contains conclusions. A deeper understanding of how the structure and properties of the composites depend on their preparation procedure will allow to improve the working parameters and widen their application area.

\section{EXPERIMENTAL}

$\mathrm{Bi}-\mathrm{Cu}$ and $\mathrm{Bi}-\mathrm{Ni}$ composites were synthesized by stirring $\mathrm{Cu}$ and $\mathrm{Ni}(3-5 \mu \mathrm{m})$ into a Bi melt in a medium-frequency induction electric furnace under an inert atmosphere. The raw materials were bismuth with a purity of $99.999 \%$, $\mathrm{Cu}$ and $\mathrm{Ni}$ powder with a purity of $99.99 \%$.

The samples for the microstructural investigation were prepared following the standard metallographic procedure of grinding and polishing. Microstructural examination was carried out using a Jeol JSM-6700F operating at $20 \mathrm{kV}$. The phases present in the alloy were examined by electron probe microanalysis (EPMA).

$\mathrm{X}$-ray diffraction studies were performed at room temperature using a STOE Transmission Diffractometer System STADI P, whereas high-temperature diffraction 
studies were carried out using a high-temperature diffractometer with a special attachment, which allows to investigate the solid and liquid samples at different temperatures, up to $1800 \mathrm{~K}$. $\mathrm{Cu}-\mathrm{K}_{\alpha}$ radiation, monochromatized by means of LiF single crystal as a monochromator and Bragg-Brentano focusing geometry were used. The scattered intensities were recorded as a function of the scattering angle in the range $1 \AA^{-1}<\mathrm{k}<7 \AA^{-1}$ with an angular step of $0.05^{\circ}$ within the region of the principal peak and $0.5^{\circ}$ for the remaining values of the wave vector. The measurement of the scattered intensity was performed with an accuracy of at least $2 \%$. In order to obtain more accurate scattered intensities, the scan time was set to $100 \mathrm{~s}$. The diffracted intensity was recorded using a $\mathrm{NaI}(\mathrm{Tl})$ scintillator detector together with an amplification system.

\section{RESULTS AND DISCUSSION}

The alloys were investigated at temperatures between solidus and liquidus lines and above the liquidus line. These temperatures were chosen symmetrically relative to the melting point, so the $\mathrm{Bi}-\mathrm{Cu}$ and $\mathrm{Bi}-\mathrm{Ni}$ composites were investigated at the temperatures of $615 \mathrm{~K}$ and $1145 \mathrm{~K}$. The duration of stirring at $615 \mathrm{~K}$ was set at 60 and $180 \mathrm{~s}$. It was found empirically that to observe distinctly the result of interaction between particles and melt, the concentration of the high-melting component should be close to 15 at $\%$.

The microstructure of the $\mathrm{Bi}_{0.85} \mathrm{Cu}_{0.15}$ composite after temperature treatment at $615 \mathrm{~K}$ is shown in Fig 1. As can be seen, the $\mathrm{Cu}$ powder was mainly coated with bismuth. By means of detailed EPMA analysis it was established that no chemical interaction occurred between $\mathrm{Bi}$ and $\mathrm{Cu}$, which is in agreement with the equilibrium phase diagram [10]. Similar features can be observed in the X-ray diffraction patterns (Fig. 2). This figure demonstrates the existence of a $\mathrm{Bi}$ phase, as well as of a small amount of copper. Such structure was observed irrespective of the duration of stirring.

At the higher temperature $(\mathrm{T}=1145 \mathrm{~K})$, the structure of liquid $\mathrm{Bi}_{1-\mathrm{x}} \mathrm{Cu}_{\mathrm{x}}(\mathrm{x}=0.1,0.15)$ alloys was studied by means of X-ray diffraction. Structure factors (SFs) of these alloys are shown in Fig. 3. Certain general characteristics were observed as the experimental diffraction functions

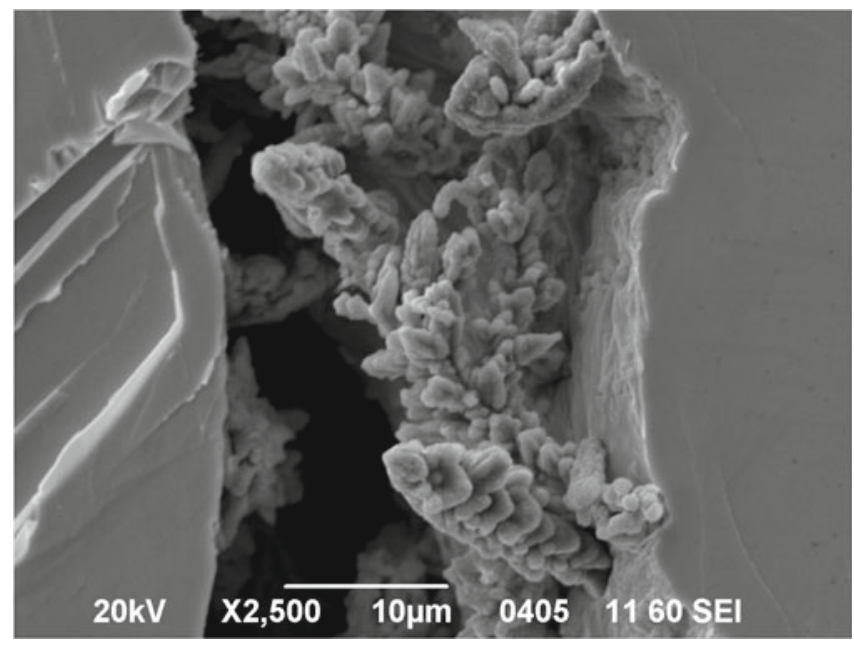

Figure 1. Microstructure of the $\mathrm{Bi}_{0.85} \mathrm{Cu}_{0.15}$ composite after temperature treatment at $615 \mathrm{~K}$

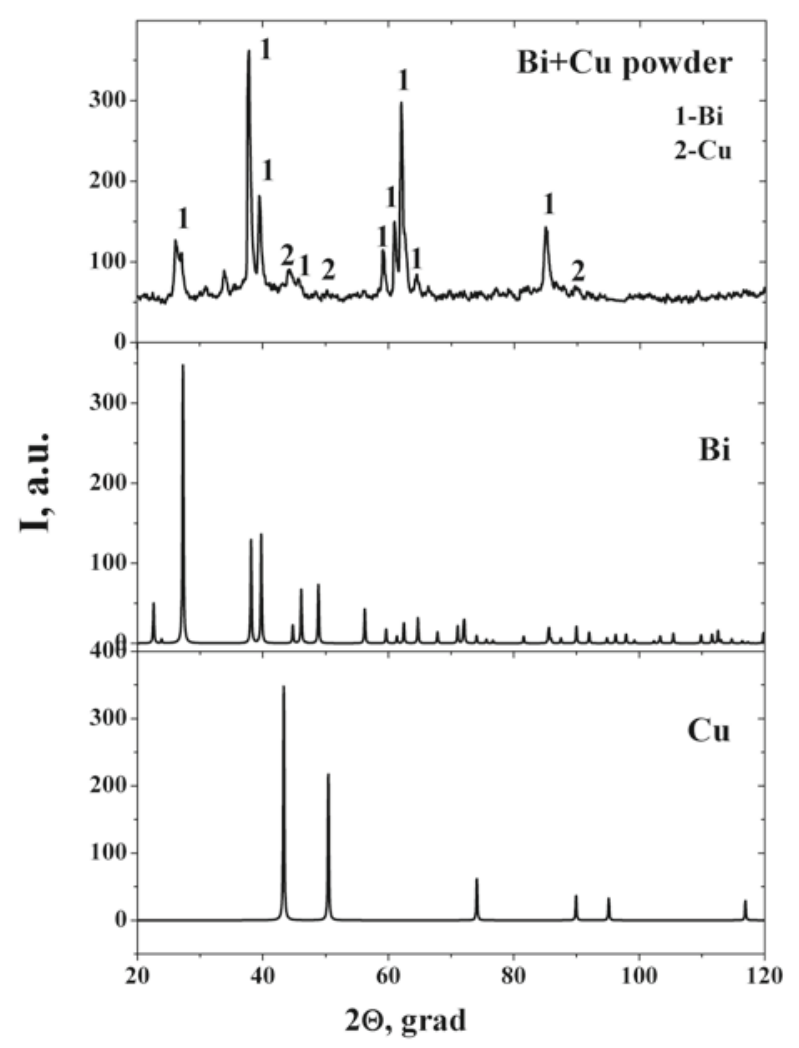

Figure 2. Diffraction patterns of the $\mathrm{Bi}_{0.85} \mathrm{Cu}_{0.15}$ alloy

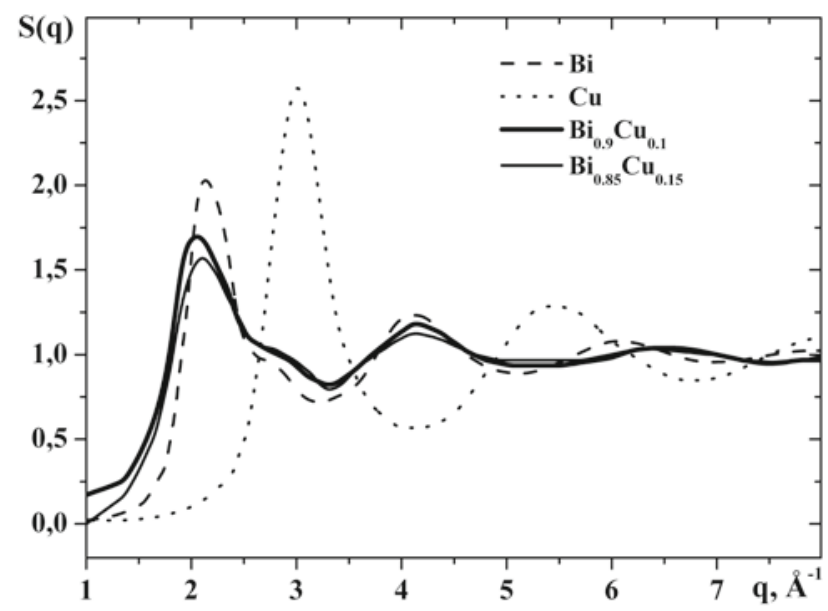

Figure 3. Structure factors of the liquid $\mathrm{Bi}_{1-\mathrm{x}} \mathrm{Cu}_{\mathrm{x}}$ molten alloys varied upon the addition of $\mathrm{Cu}$ to $\mathrm{Bi}$. The first peak in $\mathrm{S}(\mathrm{q})$ was located at $2.05 \AA^{-1}$ for 10 at $\%$ of $\mathrm{Cu}$ and shifted slightly towards $2.10 \AA^{-1}$ with an increase in the $\mathrm{Cu}$ content. The height of the peak at $10 \%$ of $\mathrm{Cu}$ was 1.69 , i.e. significantly lower than that for pure liquid $\mathrm{Bi}$ (2.04), showing further reduction to 1.57 with an increase in the $\mathrm{Cu}$ content. Another characteristic feature is the occurrence of a shoulder on the right-hand side of the principal peak of the SF present in the structure factor of liquid $\mathrm{Bi}$. The height of this shoulder gradually increased with an increase in the $\mathrm{Cu}$ content of the alloy. The changes in diffraction functions and structural parameters cannot be explained within the framework of the random atomic distribution model.

Similar conclusions can be drawn by analyzing the earlier studies on similar systems. For example, it has been shown in ${ }^{11}$ that the structure of liquid $\mathrm{Bi}-\mathrm{Ag}$ alloys cannot be described with a statistical distribution model, whereas in ${ }^{\mathbf{1 2}}$ it was assumed that structural ordering, such 
as the existence of associations or clusters, takes place in $\mathrm{Bi}-\mathrm{Ag}$ melts, and extends over a wide temperature range.

On the basis of these results, it can be assumed that the formation of self-associated clusters in the $\mathrm{Bi}_{1-\mathrm{x}} \mathrm{Cu}_{\mathrm{x}}$ melt takes place, because the hint of existence of such clusters in melt allowed us to calculate the structure factor of the investigated alloys assuming additive scattering from both the $\mathrm{Bi}$ and $\mathrm{Cu}$ regions. The according formula, involving the SFs of liquid bismuth and copper can be easily obtained:

$S(q)=C_{B i} K_{B i}^{2} S_{B i}(q)+C_{C u} K_{C u}^{2} S_{C u}(q)$

where $\mathrm{C}_{\mathrm{Bi}}, \mathrm{C}_{\mathrm{Cu}}$ are the fractions of bismuth and copper; $\mathrm{K}_{\mathrm{Bi}} \mathrm{K}_{\mathrm{Cu}}$ are the respective scattering abilities.

A similar structure was observed after the crystallization of this melt. As can be seen from Fig. 4, the $\mathrm{Cu}$-rich regions are distributed in the $\mathrm{Bi}$ matrix.

The results obtained for the $\mathrm{Bi}_{0.85} \mathrm{Ni}_{0.15}$ alloy were substantially different. This can be explained by the tendency of this alloy to form chemical compounds.

Fig. 5, panel a) shows a scanning electron micrograph of the microstructure formed by stirring the Ni particles into the Bi melt. Here, the duration of stirring was 60 $\mathrm{s}$ at a temperature of $615 \mathrm{~K}$. As can be seen from this figure, no interaction between $\mathrm{Bi}$ and $\mathrm{Ni}$ was observed and the Ni powder was not wetted by bismuth. With an increase in stirring time the structure gradually became homogeneous and the size of the particles decreased [Fig. 5, panel b)]. Therefore, by changing the duration of stirring and the temperature of the mixture of melt and powder, it was possible to control the changes in the size of powder, which showed no further changes after the reaction was complete. In such a way, one can carry out the formation of nanoscale structural units. Bi atoms, which attempt to interact with $\mathrm{Ni}$ atoms, rearrange their distribution, forming $\mathrm{Bi}_{3} \mathrm{Ni}$, as evidenced by the diffraction patterns of this composite (Fig. 6).

In order to understand the processes of structure formation in these mixtures, they were investigated not only after quenching, but also at higher temperatures (above the melting point).

The SFs showed a profile typical for a melt, not revealing any crystalline-like peaks (Fig. 7). This allowed us to observe that the Ni powder was completely diluted in liquid $\mathrm{Bi}$. The change in the principal peak profile of the

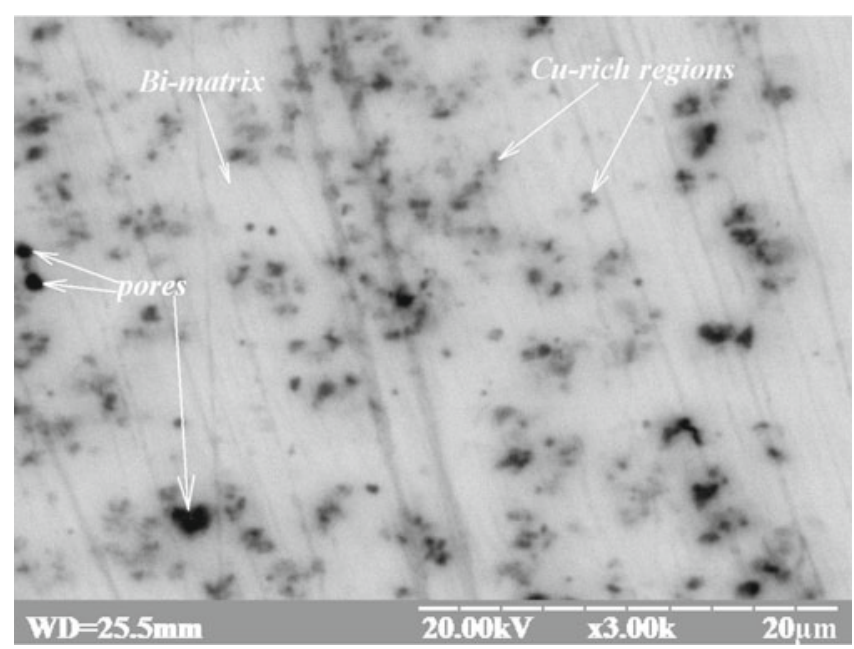

Figure 4. Microstructure of the $\mathrm{Bi}_{0.85} \mathrm{Cu}_{0.15}$ composite after temperature treatment at $1145 \mathrm{~K}$
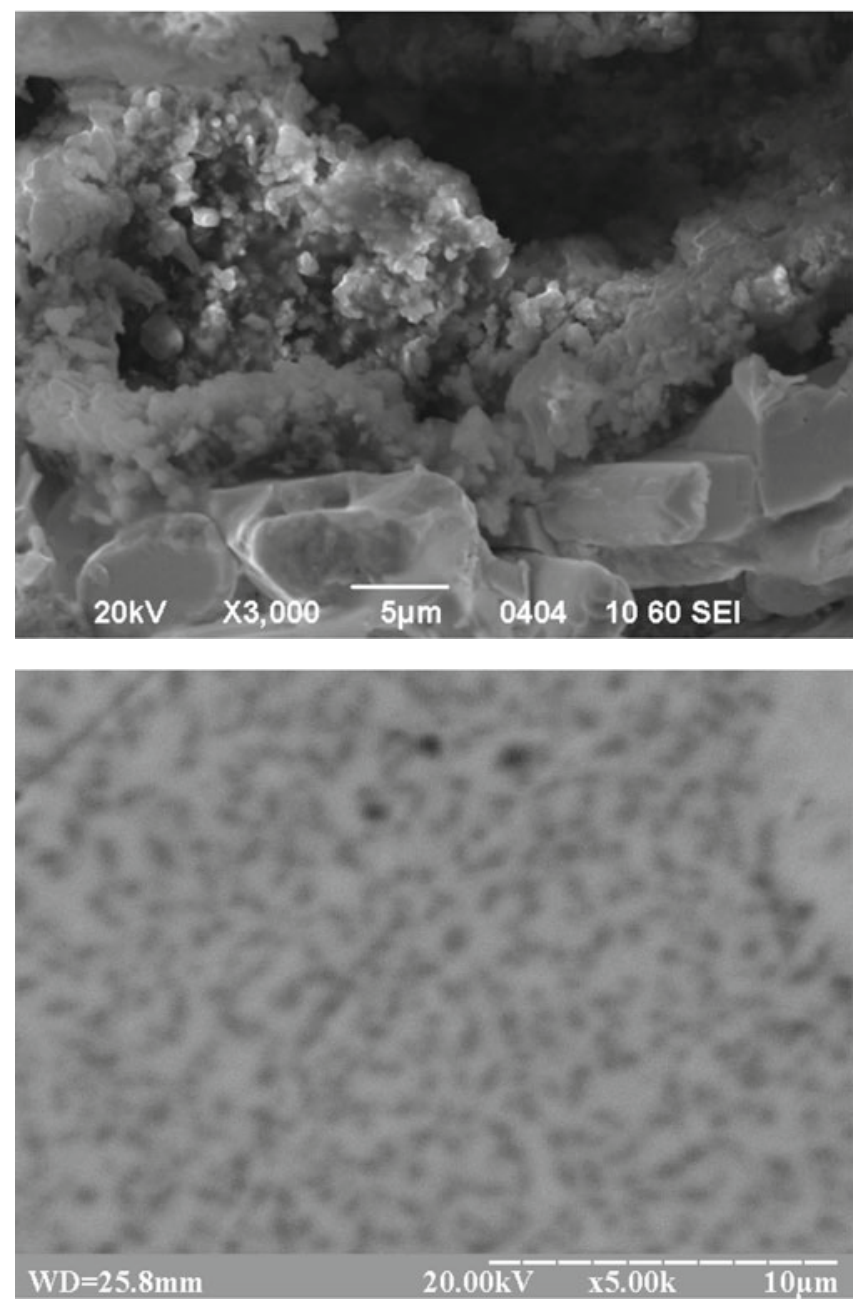

Figure 5. Microstructure of the $\mathrm{Bi}_{0.85} \mathrm{Ni}_{0.15}$ composite for different durations of stirring, a) $60 \mathrm{~s}$; b) $180 \mathrm{~s}$

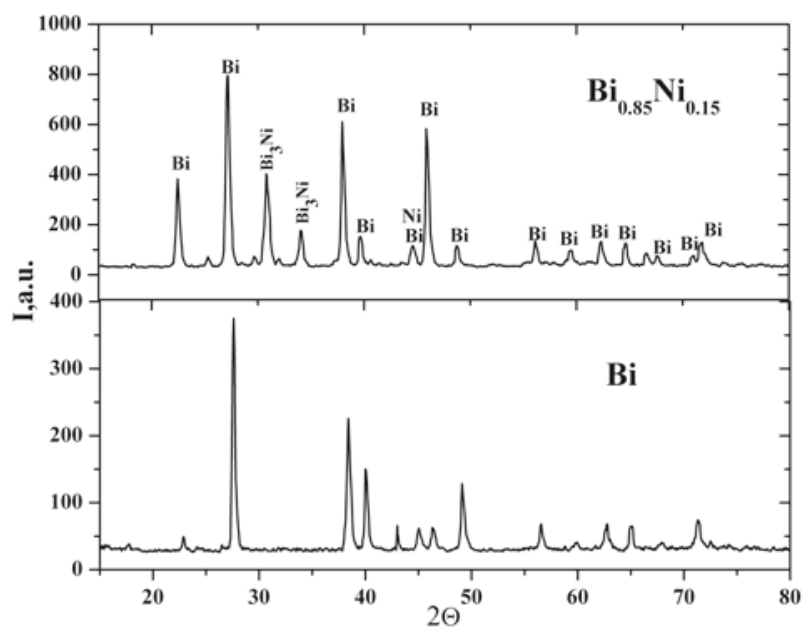

Figure 6. Diffraction patterns of the $\mathrm{Bi}_{0.85} \mathrm{Ni}_{0.15}$ alloy

SFs and the appearance of a shoulder on its right-hand side was attributed to a change in interatomic bonding. We assumed the existence of a strong chemical interaction between the atoms of $\mathrm{Ni}$ and $\mathrm{Bi}$ in liquid state. The atomic distribution in chemically-ordered structural units was determined by comparing experimental structure factors with the diffraction patterns of crystalline BiNi and $\mathrm{Bi}_{3} \mathrm{Ni}$ (Fig 7). Experimental SFs were more similar to the diffraction pattern of $\mathrm{Bi}_{3} \mathrm{Ni}$. 


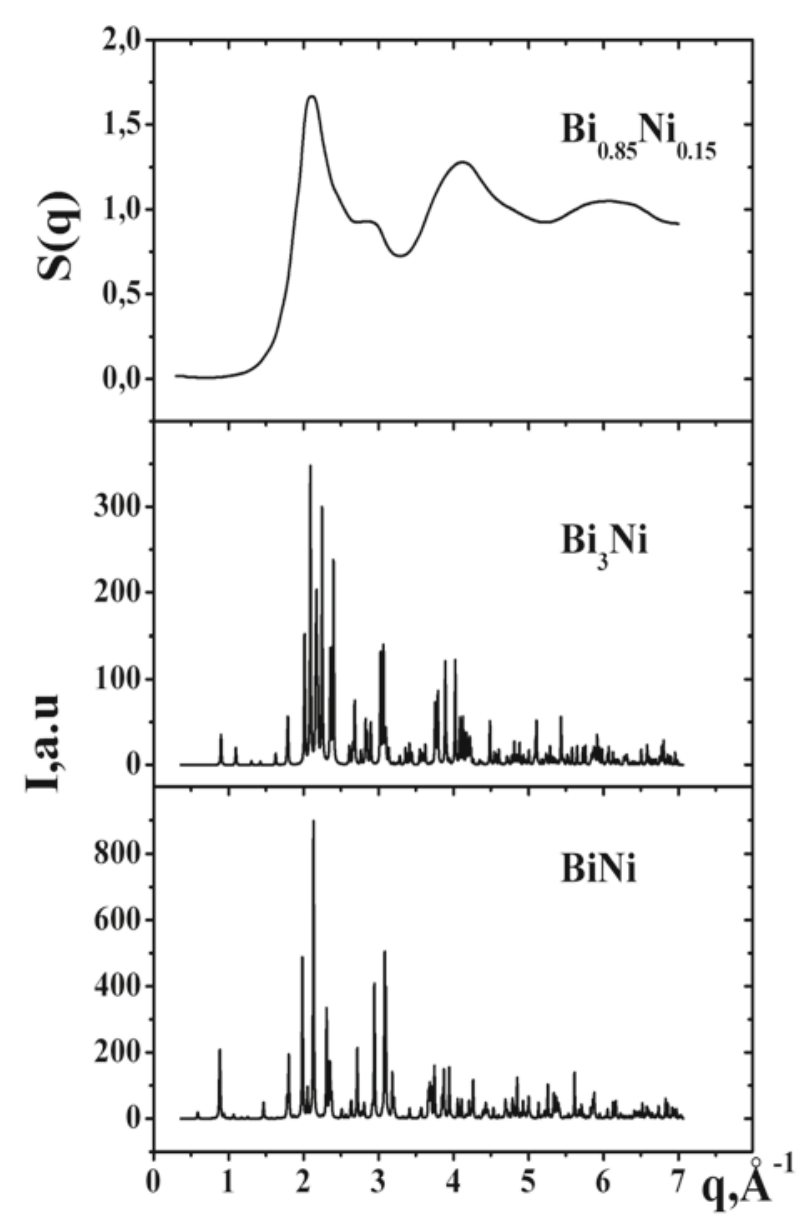

Figure 7. Experimental structure factors of $\mathrm{Bi}_{0.85} \mathrm{Ni}_{0.15}$ and diffraction patterns of crystalline $\mathrm{BiNi}$ and $\mathrm{Bi}_{3} \mathrm{Ni}$

\section{CONCLUSIONS}

The addition of $\mathrm{Cu}$ and $\mathrm{Ni}$ to the $\mathrm{Bi}$ melt at a temperature of $615 \mathrm{~K}$ promoted the formation of a composite with a Bi matrix and randomly distributed particles of $\mathrm{Cu}$ and $\mathrm{Ni}$. The stirring of $\mathrm{Cu}$ particles into liquid $\mathrm{Bi}$ was accompanied by coating and wetting of $\mathrm{Cu}$ with atoms of $\mathrm{Bi}$. At temperatures above the liquidus line of the phase diagram, the formation of self-associated clusters of $\mathrm{Bi}$ and $\mathrm{Cu}$ was observed.

To the contrary, in the case of $\mathrm{Bi}_{1-\mathrm{x}} \mathrm{Ni}_{\mathrm{x}}$, the interaction between liquid $\mathrm{Bi}$ and the Ni particles depended on the duration of stirring. When the duration of stirring was 180 s, the microstructural analysis and X-ray diffraction analysis revealed the formation of $\mathrm{Bi}_{3} \mathrm{Ni}$. At temperatures slightly exceeding the liquidus line $(1145 \mathrm{~K}) \mathrm{Bi}_{3} \mathrm{Ni}$-like clusters were distributed in the Bi matrix.

By changing the duration of stirring and the temperature of the mixture of liquid $\mathrm{Bi}$ and powder, it was possible to vary the size of the powder. In such a way, one can carry out the formation of nanoscale structural units.

\section{Acknowledgements}

This work was supported by a grant from Fundamental Researches State Fund of Ukraine (№ F 28/ 329-2009).

\section{LITERATURE CITED}

1. Kainer, U. (2006). Metal Matrix Composites. Wiley.

2. Krishan, K. Chawla. (1998). Composite Materials Science and Engineering. (2nd ed.). Springer Science + Business Media Inc.
3. Clyne, T.W. \& Withers, P.J. (1993). An Introduction to Metal Matrix Composites. Cambridge: Cambridge University Press.

4. Rohatgi, P.K., Asthana, R. \& Das, S. (1986) Solidification, structures, and properties of cast metal-ceramic particle composites. International Metals Reviews. 31, 115-139.

5. Prasad, S.V. \& Asthana, R.(2004). Aluminum Metal Matrix Composites for. Automotive Applications: Tribological Considerations. Tribol. Lett. 17(3), 445-453.

6. Srivatsan, T.S., Sudarshan, T.S. \& Lavernia, E.J. (1995). Processing of discontinuously-reinforced metal matrix composites by rapid solidification. Prog. Mater. Sci. 39 (4-5), 317-409. DOI: 10.1016/0079-6425(95)00003-8.

7. Lavernia, E.J. \& Wu, Y. (1996). Spray atomization and deposition. Chichester: John Wiley Publishing Ltd.

8. Mei, Q.S. \& Lu, K. (2007) Melting and superheating of crystalline solids: From bulk to nanocrystals. Prog. Mater. Sci. 52(8), 1175-1262. DOI: 10.1016/j.pmatsci.2007.01.001.

9. Rinaldi, C., Chaves, A., Elborai, S., He, Xiaowei (Tony) \& Zahn, M. (2005) Magnetic fluid rheology and flows. Current Opinion in Colloid \& Interface Science 10(3-4), 141-157. DOI: 10.1016/j.cocis.2005.07.004.

10. Massalsky, T. (1998). Binary alloy phase diagrams. Ohio: American Society for Metals: Metalls Park.

11. Kaban, I. \& Hoyer, W. (2002). Interplay between atomic and electronic structure inliquid noble-polyvalent metal systems. Journal of Non-Crystalline Solids. 312-314, 41-46. DOI: 10.1016/S0022-3093(02)01647-2.

12. Okajima, K. \& Sakao, H.(1983). Densities of Liquid Bismuth-Silver and Bismuth-Cadmium Alloys. Mater. Trans. JIM 24, 216-222. 